\title{
Interrelation between procrastination and Internet addiction in high school students in the context of risks of modern education
}

\author{
Ivan Malyshev ${ }^{1 *}$, Igor Arkhipenko ${ }^{2}$ \\ ${ }^{1}$ Saratov State University, Department of pedagogical-psychology and psychodiagnostics, \\ 410012 Saratov, Russia \\ ${ }^{2}$ Saratov State University, Faculty of psychological-pedagogical and special education, \\ 410012 Saratov, Russia
}

\begin{abstract}
The article discusses manifestations of procrastination and Internet addiction in high school students within the context of risks of the modern society and education. The purpose of the study is to analyze interrelations between the phenomena of procrastination and Internet addiction in high school students' personality. The empirical study involved 120 students of the $9^{\text {th }}-11^{\text {th }}$ grades from the cities of Saratov and Balashovaged 15 to 17 . We used the questionnaire called "The Degree of Procrastination Intensity” by M.A. Kiselev (system vector psychology SVP), the technique for determining Internet addiction by S.H. Chen and the test for Internet addiction identification by Kimberly Young. We used the author's questionnaire for qualitative analysis of the interrelation between procrastination and Internet addiction of the subjects. The established relationships between the phenomena of procrastination and Internet addiction (analysis of correlation relationships, typological analysis).New data have been obtained that reveal the nature of the determination of these phenomena in a sample of high school students interacting in modern conditions of education.
\end{abstract}

\section{Introduction}

Frequent changes taking place in the modern society affect personality of young people, their ability to adapt and interact with the immediate circle. This also influences the possibility to carry out educational activities, prospects for professional self-determination, and effectiveness of entering the professional sphere. Today, the study in psychology of maladaptive behavior includes such complex phenomena as procrastination and Internet addiction.

It may actively develop against the background of other addictions, particularly Internet addiction. Development of negative changes in students' personalities, associated with these maladaptive phenomena, has been recently growing more actively in the face of risks of the modern education. This is largely due to constant innovations and changes in

\footnotetext{
* Corresponding author: iv.999@list.ru
} 
education accompanied by computerization, IT technologies, etc. The emergence of new gadgets certainly has a positive impact on the process of education at school, makes it more comfortable, affordable, and improves students' performance. At the same time, constant improvement of the process can adversely affect the immature psyche of an adolescent. Constantly emerging new technologies that are often visually perceived as effective ones cause the distraction from solving real practical problems. In addition, such visible "facilitation" often creates the students' focus on the process, rather than on the result. The young person's psyche is not always capable of coping with the increasing information flow, as well as to process digital information correctly and timely. All of this greatly increases the risks of both procrastination and Internet addiction development. In general, noticeable development of the procrastination and addiction phenomena during the early adolescence indicates the need to study the manifestation of these phenomena and characteristics of the interrelations between them.

The term "procrastination" (pro- means "forward", "instead", and -crastinus means "till next day") in the scientific sense reflects a person's tendency to constantly postpone secondary and important matters for another day or time ("till the next day"), in other words, to "cop out" of solving problems and tasks, to avoid the fulfillment of previously undertaken obligations. As it has been accurately noted in the psychological dictionary, procrastinator in adolescent slang is a "slow poke". [1]. Experts believe that such a state often becomes a mechanism for coping with anxiety, when an individual experiences agitation, believing that he is not able to cope with the task or will not be able to complete it. In addition, psychologists determine three basic criteria for the phenomenon. Modern scientists view low personal self-esteem as one of the causes of procrastination [2]. In addition, researchers determine the following foundations for the development of procrastination phenomenon. Primarily it is personality self-limitation, next its disobedience and only then focus on the process. We can say that all these causes lead to personality crisis to a certain degree (the initial stage of phenomenon development), and consequently to the pathological form of procrastination manifestation [3]. Over the recent years, modern computer information technologies and mass media have made a significant leap forward and invaded almost all social spheres. Their development does not lead to procrastination only, but to other forms of personality destruction, i.e. Internet addiction. Basically, there is a destructive change in the personality and in the psyche of young people, especially adolescents, whose personality is not always able to overcome such a powerful information flow due to insufficient social experience and lack of necessary internal adaptation reserves. L.N. Yuryeva and T.Yu. Bolbot point out the prevalence of Internet addiction among most users and define it as a compulsive or obsessive desire to be on-line, and the inability to go off-line [4]. N.P. Kirilenko states that adolescents with Internet addiction have a communication problem, associated with group inclusion. Such personality traits as severe anxiety, rigidity, low self-esteem, difficulties in accepting one's own bodily image, complicate the situation [5]. Having analyzed Internet addiction-related studies based on the example of university students, we have come to the conclusion about Internet addiction's influence on the hierarchy of young people's personal value sphere and their adaptive capabilities [6]. Another work reveals the role of adaptive potential in the prevention of Internet addiction in adolescence and youth [7]. An analysis of characteristics of personal procrastination and Internet addiction phenomena indicates certain similarities with the mental state also known as the burnout syndrome [8].

It should be noted, that studying characteristics of personal procrastination and various addiction forms assumes to use the new techniques, in other words, to rely on a systemic diachronic approach, tracking the nature of changes in various personality instances in the time perspective [9]. Scientists are also considering the possibilities of a diachronic approach to the study of socio-psychological adaptation and socialization processes, as they 
analyze the relationship and interaction between personality and environment [10]. Based on the complexity of personal procrastination and Internet addiction phenomena, there is a need to study them in interrelation with such phenomena as socio-psychological adaptability and adaptive readiness. Development of adaptive readiness under conditions of uncertainty among high school students would reduce the risks of procrastination and Internet addiction, therefore having preventive effect [11]. When creating correction programs for high school students with procrastination and Internet addiction manifestations, it is of scientific interest to study the characteristics of socio-psychological adaptation from the point of view of personality identity [12]. Also, it is necessary to use the modern techniques aimed at revealing students' personality, which creates the prerequisites for reducing personality mal adaptation risk and addiction occurrence [13]. Consideration of student's personality within the framework of adaptive readiness and from the standpoint of eco-psychological approach would mitigate the risks of maladaptive phenomena and addictions under the new conditions of modern education [14].

Thus, the problems of personal procrastination and Internet addiction currently have scientific and practical significance, therefore successful social and professional adaptation of future graduates of schools and universities as well as the effectiveness of their educational and professional activities depend on their solution. The purpose of this study, based on the above-stated, is to study the interrelation between personal procrastination and Internet addiction in high school students.

\section{Sample and research methods}

The empirical study involved 120 students of the $9^{\text {th }}$ through $11^{\text {th }}$ grade of Saratov and Balashovaged from 15 to 17 . We used the following psycho-diagnostic techniques: the questionnaire called "The Degree of Procrastination Intensity" by M.A. Kiselev (SVP), the technique for determining Internet addiction by S.H. Chen and the test for identifying Internet addiction by Kimberly Young adapted by V. Loskutova. We also used the questionnaire compiled by the author of the present article for qualitative analysis of the interrelation between procrastination and Internet addiction of the subjects.

\section{Research results and discussion}

With regard to findings of the study, $41 \%$ of the subjects (49 students) showed a high level, $25 \%$ of the high school students (30 subjects) showed a moderate level and $34 \%$ (41 high school students) showed a low level of procrastination(arithmetic average value is 5.4). The perfectionism index in 14 (12\%) subjects is at a high level (arithmetic average value is 3.5). According to the scale of procrastination anxiety, 32 (27\%) subjects showed a high level (arithmetic mean value is 4.4). It is noticeable that a significant part of high school students have a high degree of procrastination (more than $41-45 \%$ of the subjects, depending on the scales of procrastination). In this case, the motivational insufficiency indicator has the greatest influence on the procrastination level. Subjects with a high level on this scale are characterized by negative changes in the motivational component of their personality, which is manifests itself through difficulties in performing the task.

Having used the H. Chen's technique, we have discovered the following about high school students 'Internet addiction: 52 subjects (43\%) of high school age are subjected to Internet addiction development. These students are in a borderline state between the status of a regular user and an Internet addicted person. 50 subjects(42\%) were acknowledged as Internet addicted, according to the results of the diagnostics. Uncontrolled pastime on the Internet is typical of high school students. They are distinguished by high degree of 
emotional-cognitive involvement in the media process. Accordingly, staying on the Internet is becoming their leading goal; they derive satisfaction of their emotional and communicative needs from the media space. Internet addicted students are characterized by irrational states of the emotional-volitional sphere, as well as low communicative abilities in the real society. 18 subjects (15\%) showed a low level of Internet addiction. These high school students have a measured, focused length of the Internet use and good interpersonal interaction in the real world. The arithmetic mean value characterizing the indicator of high school students 'Internet addiction according to Chen's technique is 59.1. In order to increase the reliability of the previous study, we used the "Kimberly Young Internet Addiction Test" technique, adapted by V. Loskutova. From the results it follows that 62 subjects (52\%) are classified as tempted users. Representatives of this group are distinguished by lowered self-control skills of spending time on the Internet. According to the results of the technique, 40 high school students (33\%) can be considered as Internet addicted. The arithmetic mean value characterizing the indicator of high school students Internet addiction using the Kimberly Young technique is 70 . On average, a significant number of the subjects(high school students)have strong Internet addiction (from 35 to $42 \%)$.

Based on the results of the author's questionnaire, 58\% of the students (70 respondents) are online for about 5 hours a day, which clearly exceeds the permissible norms of the information load on the psyche. That means that most respondents daily overload their brain with excessive media consumption, which may well be one of the significant reasons for the development of procrastination in this age group. Furthermore, 78 surveyed high school students $(65 \%)$ do not believe that their online presence often distracts them from any activity in the real world, 72 respondents $(60 \%)$ stated that they do not experience emotional discomfort because of not paying enough attention to important matters in their activities. Answering the next question, 62 respondents (52\%) wrote that they do not have areas of self-realization that reflect motivation for achievements (playing sports, attending clubs, playing music, etc.) and therefore return to real life more often and rather because of fear of punishment (avoidance motivation - "fear of responsibility"). In general, the results obtained during the survey completely correlate with the standard testing data.

Next, we carried out typological analysis in order to identify significant differences in the procrastination characteristics (see table). The sample of high school students was divided into two groups with extreme values of the Internet addiction level, with the highest and lowest rates, respectively (Table 1).

Table 1. Characteristics of the procrastination indicator in high school students depending on their Internet addiction level.

\begin{tabular}{|c|c|c|c|c|}
\hline $\begin{array}{c}\text { Procrastination } \\
\text { indicator }\end{array}$ & $\begin{array}{c}\text { Student's t- } \\
\text { test }\end{array}$ & $\begin{array}{c}\text { (significance by } \\
\text { Student's t-test) }\end{array}$ & $\begin{array}{c}\text { Mann- } \\
\text { Whitney test }\end{array}$ & $\begin{array}{c}\text { (significance } \\
\text { by Mann- } \\
\text { Whitney U- } \\
\text { test) }\end{array}$ \\
\hline $\begin{array}{c}\text { General } \\
\text { procrastination }\end{array}$ & 9,0 & $\mathrm{p}<0,01$ & 2 & $\mathrm{p}<0,01$ \\
\hline $\begin{array}{c}\text { Motivational } \\
\text { insufficiency }\end{array}$ & 8,1 & $\mathrm{p}<0,01$ & 3 & $\mathrm{p}<0,01$ \\
\hline Perfectionism & 4,3 & $\mathrm{p}<0,01$ & 21 & $\mathrm{p}<0,01$ \\
\hline $\begin{array}{c}\text { Procrastination } \\
\text { anxiety }\end{array}$ & 5,1 & $\mathrm{p}<0,01$ & 18 & $\mathrm{p}<0,01$ \\
\hline
\end{tabular}

Based on the results of calculation of the parametric statistical Student's t-test and the non-parametric Mann-Whitney U-test it was noted that the values of the procrastination 
indicator on all scales of the technique statistically significantly differ depending on the subjects' Internet addiction level.

According to the results of the correlation analysis using the Pearson's chi-squared test, we found a positive correlation between the general procrastination indicator and Chen Internet addiction level $(\mathrm{r}=0,839 ; \mathrm{p}<0.01)$, as well as between the general procrastination indicator and Kimberly-Young Internet addiction level $(\mathrm{r}=0,796 ; \mathrm{p}<0,01)$. This correlation relationship is characterized by strong, direct, two-way interrelation. Accordingly, the higher the general procrastination indicator of high school students is, the higher their Internet addiction indicator is. It is possible that the procrastinator actively uses the Internet space in attempts to replace thoughts about fulfillment of the upcoming work. At the same time, practically unrealizable pastime in the virtual space creates the prerequisites for high school students to develop deviations in the ability to adequately assess their psychoemotional state in the Internet space. This process creates excellent conditions the further development of Internet addiction in high school students. We have discovered positive correlation interrelation between the procrastination indicator of motivational insufficiency and Chen Internet addiction level $(\mathrm{r}=0,784 ; \mathrm{p}<0,01)$, as well as between motivational insufficiency and Kimberly Young Internet addiction level $(\mathrm{r}=0,714 ; \mathrm{p}<0,01)$. This interrelation may indicate a decrease in educational and work-related motivation and a constant need to be in the Internet space. Similarly to many types of addictions, Internet addiction completely distorts the motivational-demanding sphere of a high school student by placing being in the media space above all. We found a positive correlation interrelation between the procrastination perfectionism indicator and Chen's Internet addiction level $(\mathrm{r}=$ 0,556; $\mathrm{p}<0,01)$, as well as between the perfectionism scale and Kimberly Young Internet addiction level $(\mathrm{r}=0,394 ; \mathrm{p}<0,01)$. According to this interrelation, we can say that the irrational overestimation of one's own attitudes towards the required work and low selfesteempush the subjects to frequent, aimless pastime in the media space, thus, stimulating constant emotional tension and developing Internet addiction. We have also found positive correlation interrelation between the procrastination anxiety indicator and Chen's Internet addiction level $(\mathrm{r}=0,702 ; \mathrm{p}<0,01)$, as well as between procrastination anxiety and Kimberly Young's Internet addiction level $(\mathrm{r}=0,658 ; \mathrm{p}<0,01)$. In accordance with the discovered interrelations, the higher the level of procrastination anxiety is, the more significant the manifestations of high school students Internet addiction are, and vice versa. In such a stressful state, the processes of personal self-determination and interpersonal interaction are disrupted. In other words, because of these conflicts with the surrounding society, a high school student begins to perceive the outside world hostilely, and long "immersions" into media space can cause the development of Internet addiction in high school students.

\section{Conclusions}

Therefore, the obtained results indicate the interrelation between personal procrastination and Internet addiction phenomena in high school students. This follows from the results of qualitative and quantitative data analysis, correlation analysis of interrelations and typological analysis. Thus, we found statistically significant differences for all procrastination indicators of subjects with high and low levels of Internet addiction, i.e. "General procrastination", "Motivational insufficiency", "Perfectionism", and "Procrastination anxiety". We can definitely speak about the dependence of procrastination on the Internet addiction level. In its turn, Internet addiction affects the characteristics of the high school students' personal procrastination (correlation, typological analysis, qualitative analysis of questionnaire results). In the course of the study, we singled out a pattern, which shows that high school procrastinators use the Internet space as a substitute 
for thoughts about the carrying out certain upcoming activities. This further creates the prerequisites for Internet addiction development in students.

Modern educational conditions can increase the risks that mal adjust the personality of students against the background of Internet addiction, procrastination, or other destructive changes. Based on the results of an empirical study, it is necessary to create corrective programs aimed at preventing procrastination and Internet addiction of students.

\section{References}

1. B.G. Meshcheryakova, V.P. Zinchenko, Big Psychology Dictionary, (PrimeEUROZNAK, St. Petersburg, 2009)

2.Ya.I. Varvaricheva, Issues of Psychology, 3 (2010)

3.Yu.D. Babayeva, A.V. Novova, Ya. I. Varvaricheva, Materials of the Anniversary Conference 130 Years of the Psychological Society Organization at Moscow University (2015)

4.L.N. Yurieva, T.Yu. Bolbot, Computer Addiction: Developing, Diagnosis, Correction and Prevention (Porogi, Dnepropetrovsk, 2006)

5. N.P. Kirilenko, Materials of the 3rd Scientific-Practical Conference with International Participation: in 2 Parts (2015)

6. I.V. Malyshev, A.K. Sultanova. In the World of Scientific Discoveries 3.3, 51 (2014)

7.M.V. Grigorieva, A.R. Vagapova, L.E. Tarasova, A.V. Kashcheeva, I.V. Malyshev, M.S. Tkacheva, T.V. Khutoryanskaya, T. N. Chernyaeva. Adaptation Readiness of a Personality in Modern Conditions of Society Development, (Saratov, 2016)

8. I.V. Malyshev, Saratov University News. Series: Philosophy. Psychology. Pedagogy. 3, (2011)

9.R.M. Shamionov, Psychological Studies 6, (2013)

10.M.V.Grigorieva, Saratov University News. New series. Series. Philosophy. Psychology. Pedagogy. 13, (2013)

11.R.M. Shamionov, Russian psychology journal, 14, (2017)

12. V.V. Konstantinov, V. V Dyakov, Theory and Practice of Social Development, 12, (2015)

13.V. V. Konstantinov, Actual Problems of Modern Psychology Development Prospects, 1, (2014)

14.M.V. Grigoryeva, Siberian Pedagogical Journal, 1, (2017) 